\title{
The Convergence of Endogenous and Exogenous Influences on Consumer Behavior
}

\author{
Alexandru-Bogdan Ursoiu ${ }^{1}$ \\ The Bucharest University of Economic Studies, Romania ${ }^{1}$
}

\begin{abstract}
Consumer behavior is a central theme for the science of marketing, its research growing in importance over the last years, due to the need for detailed information in order to explain and to predict how consumers make their decisions. The research on that subject keeps developing continuously, while the interest is both academic and practical, in order to identify and investigate the factors that influence behavior. The present paper explores the influence of endogenous and exogenous factors, by analysing the content of 73 scientific publications. These influences are explored and their synergies are explained. While the influence of each factor can be addressed individually, the integration of those influences brings new useful information on what shapes and guides consumer decision-making. In that regard, the convergence-based approach highlights the elements that are relevant for the marketing efforts to better satisfy the customers and improve business outcomes.
\end{abstract}

Keywords: Consumer behavior, Buyer decision-making, Endogenous influences, Exogenous influences

\section{INTRODUCTION}

The modern marketing approach, both at theoretical and practical level, is decisively focused on the consumer, whose needs and desires are of the greatest interest for the successful companies. For the manifestation of behavior regarding the choosing, using and disposing of goods and services, the stimuli determines both rational and emotional reactions in the minds of consumers, which in turn generate certain behavioural responses [1]. The nature of these responses is influenced by the multitude of factors relevant to behavior. Behavior is a dynamic process that is definitely exceeding the level of exchange where the consumer gives money to receive goods and services [2], becoming one of the most important components of the economy, due to relevance in flows of resources. The current context of globalization is characterized, among other things, by the fact that in order to meet the needs through the market, consumers have at their disposal a very wide range of goods and services, which, in addition to the implications of increasing competition between companies, it also supports a value of consumption, an important part of social life [3]. In today's world of business, the marketing acknowledges that the behavior of consumers is influenced by many factors, some of them relatively easier to discern, while others being profound and sometimes even elusive. In that regard, the precise identification, the proper evaluation and the determination of influences' synergies on behavior are providing a very valuable support for the running of every business that aims to adapt to the market demand and to keep succeeding on the long term.

\section{MATERIALS AND METHODS}

This study is based primarily on content analysis of data from scientific books and articles regarding consumer behavior and its related topics. Each endogenous and exogenous factor of influence on behavior is presented, its impact on various components of behavior is highlighted and the relations to the other factors are discussed. The data is analysed and the intermediary results are further correlated in the context of influences on the consumer's manner of thinking and acting, resulting new meaningful information. Consequently, based on a process of synthesis, the most relevant conclusions are presented, with the desideratum to provide support for planning viable marketing strategies aimed at directing the business resources according to the specifics of consumer behavior.

\section{RESULTS AND DISCUSSION}

In the general sense, the influences can be categorised in two main branches, as either directly observable or belonging to way the consumer's mind relates to self and to the environment [4]. The first category of directly observable factors is made of demographic, economic, marketing mix specific and situational influences. This paper addresses the second category of influences. That is including two groups, namely endogenous influences that encompass perception, learning/personality, motivation and attitude, respectively exogenous influences represented by family, belonging groups, reference groups, social class, culture and subculture. 


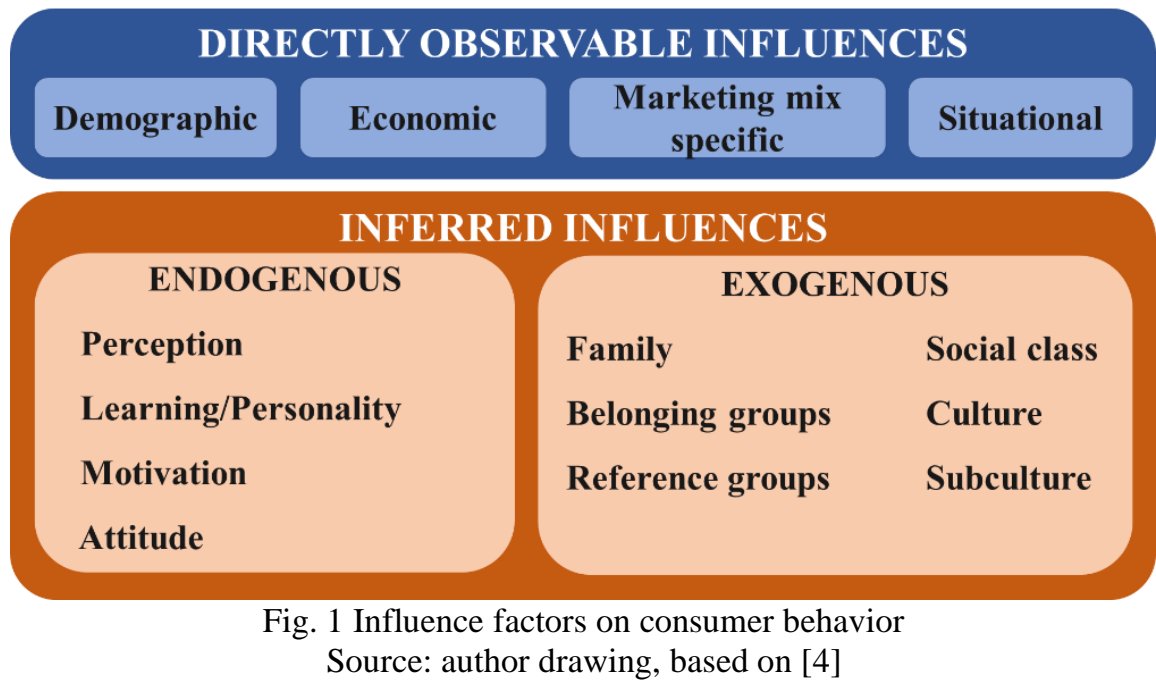

Perception is how sensory information is organized, construed and experienced consciously. This assumes a mental processing, with sensory information from environmental stimuli causing specific processes by integration, as well as a top-down processing associated with how existing elements such as experience and expectations determine stimulus recognition processes [5]. In the context of the bottom-up processing, stimulant factors are recorded in sensory memory, and are still subject to processing in the nervous system, in order to ultimately to be placed in lasting memory. Processing is done in this case starting from a relatively small information packs represented by stimuli, to result in an overview, such as a pattern [6]. On the other hand, top-down processing is based on elements such as experience, expectations, needs, interests, aspirations, and so on, which determines the pattern of information extraction, the information exceeding the stimulus itself and being carried out a search process a the most relevant meanings. This top-down scroll, as a rule, a stricter orientation of thought during the analysis and implies a greater mental effort [7]. Perception can substantially influence the purchase intention and can be a fair forecasting factor of consumer behavior [8]. As illustrated in [9], the cognitive process associated with perception is determined by four components that validate the notions for products and services: recognition, evaluation, reflection and reconstruction.

Amplification or, where appropriate, inhibition of attention, combined with emotional control elements, can determine overvaluation or sub-evaluations in the mental as a result of the processes associated with the processing of information. Perceptual selection correlates to multiple levels of information processing and tends to positively influence consumer assessments, while on the opposite pole perceptual inhibition in a competitive stimulus environment tends to lead to negative assessments [10]. The effort required by the mental processing of perceived information may also have an influence on the assessment, given that the emergence of factors that make it difficult to lead to underestimates from individuals [11]. The overall objectives pursued by consumers tend to put their mark on the selection of inputs of stimuli by amplification or inhibition of sensitivity, as well as through the tendency to put it in a favourable light or not [12] and studies such as [13] indicated that consumer emotions can substantially influence their perception and as a whole their behavior towards services. The perceptions of the risks associated with the use of a product or service are also important. Among the categories of risk envisaged by consumers can be mentioned the financial associated with the possibility of affecting the material situation, the social one associated with the possibility of the condition of the status, the psychological associated with psychic comfort and so on [14]. These perceptions influence many aspects [15], such as decision-making, value assessment, relationship with the seller and so on.

Regarding learning / personality, knowledge is composed of two main groups of elements, those associated with content and those associated with structuring, and is the basis for assimilating new information by categorization and understanding. Content reflects the data that consumers have accumulated on organizations, product categories, instructions for use, and so. Categorization occurs by identifying individuals an element that was perceived on the basis of similarity with existing representations, while by understanding they carry out a mental process of correlating information with the already involved data to enhance the knowledge they hold [16]. Considering that in many cases, consumers do not have complete information on the attributes of products and services that interest them, there is a certain degree of insecurity on their part, to reduce their organizations to act, through marketing efforts to transmit the idea of quality [17]. Memory is more than the recording of past elements, being associated, for an instance, with the learning capacity or the influence of experience on behavior, including the training of preferences [18]. The memory can be hierarchized at a very short term, then at short-term fixation through discursive and imaginative processes, in order to be 


\section{International Advanced Research Journal in Science, Engineering and Technology}

Vol. 8, Issue 2, February 2021

\section{DOI: $10.17148 /$ IARJSET.2021.8222}

able to fix long-term episodic or semantics [16]. In cognitive terms, learning is a result of mental processes, focusing on creating assumptions by consumers who will act in accordance with them [19]. Although support through marketing steps of organizations' stimuli can produce effects in the desired sense, behavior is rather influenced by the actual support of the stimuli, but by what consumers think of support, they actually pursuing benefits for itself [20]. Given that a consumer who could not produce changes in his environment would be unlikely to change his behavior, he might make attempts on several marketing stimuli and retain the one who brings him the one that more favourable result [21]. Consumers generally learn both consciously and unconsciously, but in the second case it would mean that they would not be aware of the environment. It can be said that this differentiation mainly concerns situations where learning, as a continuous process, occurs in the first case for individuals that are aware of what they learn and in the second case for those who do not currently become learning [22]. In the case of products and services presenting novelty for the consumer, the learning process can take an observational form through mediated innovation [23], which, in conjunction with the influence exerted by the personality, makes consumers perceive the value of the offer, which generates a better assessment of its attributes [24].

The individuals might appreciate a compatibility between consumer personality and brand characteristic. Thus, the marketing could pursue a personification process that individualizes [25] and encourages consumers to establish affective links with the brand by supporting favourable reactions [26]. Starting from a conclusions of a study which showed that cognitive and affective representations are usually activated in parallel [29], further research has confirmed that a high compatibility between the personality of the consumer and the brand will be generated on the basis of made assessment, trust and commitment [27]. Studies such as [28] supported the idea that the degree of compatibility between the personality type of consumers and the offer characteristics is very important. Consumers characterized by a mental stability-based configuration are generally being influenced by a company's good image and reputation, while individuals with growth-oriented mental configurations are more likely to appreciate punctual improvements in offer [30].

Consumer motivations express their willingness to focus their attention, to define their goals, to shape the decisions and to make the necessary efforts to achieve the objectives [31]. Through motivation, individuals are supporting their goaloriented behavior, conducting cognitive processes and behavioural processes in order to achieve their objectives [20]. Essentially, motivation is manifested as a result of the emergence of a tension, which is sufficiently pressing to determine the individuals to satisfy it [32] and starts from the transformation of a need into a felt motivator. The motivation can operate at a basic cognitive level, stimulating consumers' commitment to marks before their acquisition and use [33]. Rani [34] encourages companies to precisely identify the needs that can become motivations for the choice of goods and services offered so that they respond accurately and provide the best solutions for those needs. Intrinsic motivation may be associated with the gratitude resulting from an activity itself, without external pressure or the search for a reward, while the extrinsic motivation is associated to achieving a more specific objective or reward [35]. In most cases, motivation is not based solely on one aspect, but includes several elements that each have its role in influencing consumers to choose certain brands [36]. Regarding the attributes of goods and services, consumer motivation can have in some situations a very complex character, including aspects like motivational compatibility, the need for conflict mitigation, the importance of compromises and so on [37].

Attitudes are predispositions to respond favourably or unfavourably in relation to an element [38], being based on evaluative judgments, supported on easy-to-access elements, benefiting from high trust, and the degree of uncertainty that is associated with them tends to be reduced. On the other hand, weaker attitudes consider elements that are harder to retrieve from the memory, do not enjoy special confidence and have a higher degree of uncertainty [39]. The relationship between attitudes and behavior is a solid one, which can be addressed from three perspectives: the one in which behavior is a result of attitudes, the one in which attitudes are in turn a result of behavior and that behavior is an indicator of attitudes [40]. To make evaluations, consumers combine factors in different ways, based on the granting of similar importance or, on the contrary, favouring certain elements to the detriment of others. Practically, attitude components can influence in the same direction or may be divergent, so apparently similar attitudes can actually rely on different factors [41].

Given that attitudes are predetermined assessments, they allow consumers to manage relationships with the complex environment in which they live without having to permanently resume the analysis on, for example, what brand to purchase. In the formation of these attitudes, the affective, cognitive and acting elements can be combined in various ways, with notable influences from the learning mechanisms and biological predispositions of individuals [42]. In a cognitive approach of consumer behavior, there is a flow based on beliefs - affectivity - behavior, in an actional approach the flow is beliefs - behavior - affectivity, and in an affective approach the flow is affection - behavior - beliefs [43].

As the family is considered to be able to generate a high influence on consumer behavior, [44] shows that it puts the individual in contact with the brands used in the household, ensuring a higher level of knowledge and becoming associating them beneficial with memories. Given that the members must satisfy their needs usually on a common pool of resources [45], the family exerts a direct and ubiquitous influence on consumer behavior. Although a family can jointly 


\section{International Advanced Research Journal in Science, Engineering and Technology}

Vol. 8, Issue 2, February 2021

\section{DOI: $10.17148 /$ IARJSET.2021.8222}

use the products, its members fulfil roles that can be individualized, such as the initiator, intelligence harvester, influencer, decision-maker, or user, these roles adapting and changing between members according to situation over time [46]. The initiator is that family member aware of the need and who initiates the decision-making process, the gatherers of information have a certain experience and/or are interested in the specificity of the choice, those with influence exert it especially in terms of alternatives subject to evaluation, the criteria of choice and the results, while the decision-makers are those who, individually or jointly within the family, draw the conclusion on their choice, the purchaser performs the actual transaction, and the users are the final beneficiaries [47]. Given that family-exerted influences on consumer behavior depend on the life cycle stage, aspects such as age, matrimonial status, presence of children in the household, or their age should also be considered [48].

As a social structure, belonging groups are based on rules that influence both formally and informally behavioural patterns by rewards such as social acceptance and sanctions such as marginalization. As noted in [49], building a belonging in a group involves more than identifying and selecting it, as consumers also use knowledge about choosing the products and coordinating the appearance of the body in ways to indicates affiliation to a group in a socially legitimate manner. In this respect, [50] shows that individuals behave in a certain way as a result of the effect of the social group instructions and the support they benefit from it, and the influence of membership groups is manifested by the statute, which determines voluntary compliance of consumers, and through power, which determines the imposed one. According to [51], the subject of consumption can also be regarded as what the group uses to build practices, identities and meanings in order to establish an image of the environment and the orientation of experiences in the lives of his members. [52] concludes, similarly, that beyond the specific activities of the individual, there will always be the need to act in cooperation with others to meet the common needs of the group. According to [53], the identity of the consumer expresses his opinion on himself, as well as the way he believes he is regarded by others, and consumers who have integrated a brand in their personal and social identity are predisposed to protect that brand and make considerable efforts to maintain the relationship. Individuals tend to build their identity, including consumer activities, in a way that contributes to balancing the personal perspective with group opinions [54].

As shown by [55], the impact of reference groups on behavior can be highlighted, mainly in the choice of specific goods and services, the choice of product categories or the choice of a particular brand. Consumers can establish links between reference groups and the brands chosen by their members, being able to transfer certain meanings of these marks on the self, preferring those goods and services that have relevant meanings in relation to aspects of self-concept [56]. Mainly, consumers tend to affiliate with reference groups to gain information, obtain rewards, or avoid sanctions, as well as for self-image reasons [57]. At the informational level, these groups provide a contribution of knowledge about their members, other people, or elements of the marketing environment. Sometimes consumers look for information in order to reduce the risks associated with receiving a service or to acquire skills on certain desired behaviours. At other times, the information is transmitted involuntarily to consumers, based on observation of the actions of the members of the reference group. A third possibility is the deliberate popularization by members of a reference group of activities. In terms of usefulness, the influence is accentuated to the extent that consumers consider that the reference group can offer rewards or impose sanctions, that their own behavior can be seen by group members, and that those rewards or sanctions are sufficiently relevant. At the level of individuals' self-image, the influence is determined by the fact that reference groups are associated in a social context with a series of values, beliefs, objectives, norms of behavior, lifestyles and so on. [58] conclude that consumers tend to prefer products and services associated with those reference groups that symbolize desirable aspects of self-image.

On general terms, the social class is determined on the basis of socio-economic status, assessed on the basis of occupation, level of education and income level, considering that differences in status reflects differences in access to financial and social resources [49]. Given the existence of a social stratification, belonging to a social class can be a construction that integrates more elements with impact on consumer behavior in a single synthesis factor, but it tends to no longer be characterized by stiffness as in the past but to show a growing fluidity in the modern social context [59]. As the social class indicates a position of individuals in society, the preferences for goods and services and the choice of acquisitions depend on the way in which consumers place in the social stratification [48]. Given that individuals tend to interact more often with those in their own social class, [55] consider that the influence within it is usually stronger than those coming from the other classes without excluding the consumer's ability to pass through over time in one class to another.

As expressed in [60], the influence of the social class on behavior can also be revealed in an extended context, for example by studying the pyramid of needs proposed by Maslow - physiological, security, belonging, esteem and self-analysis, as well as the individualistic or collectivist character of local culture. These influences are strong [61], especially for lifestyle, well-being and consumer patterns. It is also relevant that fixing the value as a reference can be made adapting the specifics of the social class to the close context of the consumer [62]. Sometimes, consumers have a compensatory behavior based on consumption of goods and services, aiming to restore a certain status, which had been affected by 


\section{International Advanced Research Journal in Science, Engineering and Technology}

Vol. 8, Issue 2, February 2021

\section{DOI: $10.17148 /$ IARJSET.2021.8222}

other factors [16]. Sharing similar values and with common interests, consumers in a social class show a tendency to have relatively close consumer behaviours [32] and they will choose the variants they consider compatible with the class they feel belonging to. The social class therefore influences consumer behavior both on practical and perceptual dimensions.

Culture is based on issues such as nationality, language, ethnicity, education, profession, religion, family, and so on [63]. The impact of culture on consumer behavior includes a dimension associated with its characteristics and one associated with the processes carried out by it [64]. Usually, in order to be successful, companies must be those that adapt to different cultures and not try to address markets based on their own culture of origin [65]. The need to adapt the offer to cultural specifics is also supported by the conclusions of [66]. Cultural influences can also be represented by certain schemes and scenarios that individuals internalize over the years through unconscious absorption dotted occasionally with analyses on validity [67]. These knowledge structures indicate the desirable way of defining expectations, reasoning, feeling, or behaving. Culture can describe and explain how consumers address the challenges they face in fulfilling responsibilities and the fulfilment of the desires [68]. Culture can also be a substantial influence factor on the perceptions, attitudes and actual behavior of consumers [9]. On the basis of the conclusions made by [69], it can be appreciated that studying behavior in the cultural context must be a multidisciplinary character.

As groups in a broader culture, the subcultures are characterized by the existence of some similarities with those of society as a whole, but their members also demonstrating a series of values and patterns that individualize them as a subgroup of stand-alone, on criteria such as geographic, age, ethnicity, religion and so on [39]. Thus, the subcultures offer the opportunity for organizations to share consumer masses in smaller similarity-based segments, which may be easier and in relation to which marketing efforts can be adapted to achieve similar reactions on offer, based on the existence of some Similar needs and desires. As markets are globalizing as a whole, at local level, the importance of segmentation is increasing [70], in order to permanently adapt marketing efforts to the specifics of each of the relevant consumer groups. According to [71], the importance of the subculture is illustrated by the growing trend of the consumer to choose marks taking into account what is considered acceptable at its level.

There are situations in which, due to the existence of conflicts between subcultures and main population groups, some consumers might avoid or even reject the use of brands associated with subgroups that are perceived negatively in society [72]. That can become a major risk for the position of companies, because, as in [73], attempts to expand its own consumer base by addressing new subcultures can generate negative reactions from existing consumers, so the approach requires careful planning.

\section{CONCLUSION}

The consumer behavior is taking shape and is manifesting under the influence of some directly observable factors and on the other hand is subject to inferred influences from factors that are not directly observable. While the first category of demographics, economics, marketing mix and situational factors are easier to assess and controllable to some extent, the non-observable influences are of much less obvious specifics. Nevertheless, those latter factors, of endogenous and exogenous nature, can have a more profound and stronger impact on the way consumers are actually behaving on the market and on their decision-making processes. The scientific and practical efforts in the field of marketing have produces some relevant conclusion of those mechanisms of influence, while at the same time opening new perspectives of understanding the processes residing in consumer's mind. Building on the accumulated knowledge to the present moment, this paper reviews important findings about the endogenous and exogenous influences, proposing an integrating approach based on their synergy and focusing on the convergence, in order to support the better understanding and the predicting of consumer behavior.

\section{REFERENCES}

[1]. Chaudhuri, A., "Emotion and Reason in Consumer Behavior", Oxford: Elsevier, 2006.

[2]. Hazuchová, N., Stávková, J., Siedlecka, A. and Nagyová, L., "Current Aspects of Consumer Behaviour in Central European Countries”, in Perspectives on Consumer Behaviour: Theoretical Aspects and Practical Applications, Sroka, W. (Ed.), pp. 3-30, 2020.

[3]. Zak, S. and Hasprova, M., "The role of influencers in the consumer decision-making process", SHS Web of Conferences, 74, 03014, https://doi.org/10.1051/shsconf/20207403014, 2020.

[4]. Cătoiu, I. and Teodorescu, N., "Consumer Behavior", 2nd Ed., Bucharest: Uranus, 2004.

[5]. Spielman, R., Jenkins, W. and Lovett, M. (Eds.), "Psychology 2e”, Houston: OpenStax, https://openstax.org/details/psychology-2e, 2020.

[6]. Hanna, N., Wozniak, R. and Hanna, M., “Consumer Behavior: An Applied Approach”, 4th Ed., Dubuque: Kendall Hunt Publishing, 2013.

[7]. Fine, M. and Minnery, B., "Visual salience affects performance in a working memory task", Journal of Neuroscience, 29, pp. 8016-8021, 2009.

[8]. Kytö, E., Virtanen, M. and Mustonen, S., 'From intention to action predicting purchase behavior with consumers' product expectations and perceptions, and their individual properties", Food Quality and Preference, 75, pp. 1-9, 2019.

[9]. Rajagopal, “Contemporary Marketing Strategy. Analyzing Consumer Behavior to Drive Managerial Decision Making”, Cham: Palgrave Macmillan, 2019. 


\section{International Advanced Research Journal in Science, Engineering and Technology}

Vol. 8, Issue 2, February 2021

\section{DOI: $10.17148 /$ IARJSET.2021.8222}

[10]. Tavassoli, N., "The Effect of Selecting and Ignoring on Liking”, in Visual Marketing. From Attention to Action, Wedel, M., Pieters, R. (Eds.). New York: Lawrence Erlbaum Associates, pp. 73-90, 2008.

[11]. Schwarz, N., 2004, "Metacognitive experiences in consumer judgment and decision making”, Journal of Consumer Psychology, 14(4), pp. 332348.

[12]. Ferguson, M. and Bargh, J., "Liking is for doing: The effects of goal pursuit on automatic evaluation", Journal of Personality and Social Psychology, 87, pp. 557-572, 2004.

[13]. Ladhari, R., Souiden, N. and Dufour, B., "The role of emotions in utilitarian service settings: The effects of emotional satisfaction on product perception and behavioral intentions", Journal of Retailing and Consumer Services, 34, pp. 10-18, 2017.

[14]. Haghshenas, L., Abedi, A., Ghorbani, E., Kamali, A. and Harooni, M., "Review Consumer Behavior and Factors Affecting on Purchasing Decisions", Singaporean Journal of Business Economics and Management Studies, 1(10), pp. 17-24, 2013.

[15]. Munnukka, J. and Järvi, P., "The influence of purchase-related risk perceptions on relationship commitment", International Journal of Retail \& Distribution Management, 43(1), pp. 92-108, 2015.

[16]. Hoyer, W. and Macinnis, D., "Consumer Behavior", 5th Ed., Mason: South-Western, 2010.

[17]. Zhao, Y., Zhao, Y. and Helsen, K., "Consumer learning in a turbulent Market environment: Modeling Consumer Choice Dynamics after a Product-Harm Crisis", Journal of Marketing Research, 48(2), pp. 255-267, 2011.

[18]. Mantonakis, A., Whittlesea, B. and Yoon, C., "Consumer Memory, Fluency, and Familiarity", in Handbook of consumer psychology Haugtvedt, C., Herr, P. and Kardes, F. (Eds.), New York: Taylor \& Francis Group, pp. 77-102, 2008.

[19]. Solomon, M., Bamossy, G., Askegaard, S. and Hogg, M., "Consumer Behaviour. A European Perspective”, Harlow: Pearson Education, 2006.

[20]. Schunk, D., "Learning Theories. An Educational Perspective", 6th Ed., Boston: Pearson Education, 2012.

[21]. Bergiel, B. and Trosclair, C., "Instrumental Learning: Its Application to Consumer Satisfaction", Journal of Consumer Marketing, 2(4), pp. 23$28,1985$.

[22]. Kauffmann, O., Wiberg, M. and Winch, C., "On Learning (How) to Learn", in Dealing with Conceptualisations of Learning. Learning between Means and Aims in Theory and Practice, Qvortrup, A and Wiberg, M. (Eds.). Rotterdam: Sense Publishers, pp. 25-36, 2017.

[23]. Al-Jundi, S., Shuhaiber, A. and Augustine R., "Effect of consumer innovativeness on new product purchase intentions through learning process and perceived value", Cogent Business \& Management, 6:1698849, https://doi.org/10.1080/23311975.2019.1698849, 2019.

[24]. Jeong, S., Kim, S., Park, J. and Choi, B., "Domain-specific innovativeness and new product adoption: A case of wearable devices", Telematics and Informatics, 34(5), pp. 399-412, 2017.

[25]. Eisend, M. and Stokburger-Sauer, N., "Brand personality: A meta-analytic review of antecedents and consequences", Marketing Letters, 24(3), pp. 205-216, 2013.

[26]. Fleck, N., Michel, G. and Zeitoun, V., "Brand personification through the use of spokespeople: An exploratory study of ordinary employees, CEOs, and celebrities featured in advertising", Psychology \& Marketing, 31(1), pp. 84-92, 2014.

[27]. Valette-Florence, R. and Valette-Florence, P., "Effects of emotions and brand personality on consumer commitment, via the mediating effects of brand trust and attachment", Recherche et Applications en Marketing, 35(1), pp. 84-110, 2020.

[28]. Kocabulut, Ö. and Albayrak, T., "The effects of mood and personality type on service quality perception and customer satisfaction", International Journal of Culture, Tourism and Hospitality Research, 13(1), pp. 98-112, 2019.

[29]. Pham, M., "The lexicon and grammar of affect-as-information in consumer decision making: The GAIM", in Social Psychology of Consumer Behavior, Wänke, M. (Ed.). New York: Psychology Press, pp. 167-200, 2009.

[30]. Septianto, F., "Do past scandals influence the present performance? The moderating role of consumer mindset", Journal of Business Research, 106, pp. 75-81, 2020.

[31]. Grant, H. and Higgins, T., "Do You Play to Win or to Not Lose?", Harvard Business Review, 91(3), pp. 117-120, 2013.

[32]. Kotler, P. and Armstrong, G., "Principles of Marketing", 15th Ed., Harlow: Pearson Education, 2014.

[33]. Kumar, J. and Nayak, J., "Consumer psychological motivations to customer brand engagement: a case of brand community", Journal of Consumer Marketing, 36(1), pp. 168-177, 2019.

[34]. Rani, P., "Factors influencing consumer behaviour", International Journal of Current Research and Academic Review, 2(9), pp. 52-61, 2014.

[35]. Wendel, S., "Designing for Behavior Change. Applying Psychology and Behavioral Economics", Sebastopol: O’Reilly Media, 2014.

[36]. Khaniwale, M., "Consumer Buying Behavior", International Journal of Innovation and Scientific Research, 14(2), pp. 278-286, 2015.

[37]. Ozcan, T., Hair, M. and Bagchi, R., "Consumers' Self-Contradictory Behaviors for PostPurchase Product Configurations", Journal of Marketing Theory and Practice, 27(1), pp. 19-37, 2019.

[38]. Oskamp, S. and Schultz, W., "Attitudes and Opinions", 3rd Ed., Mahwah: Lawrence Erlbaum Associates, 2005.

[39]. Kardes, F., Cronley, M. and Cline, T., "Consumer Behavior", Mason: South-Western, 2011.

[40]. Jaccard, J. and Blanton, B., "The Origins and Structure of Behavior: Conceptualizing Behavior in Attitude Research", in The Handbook of Attitudes, Albarracin, D., Johnson, B. and Zanna, M. (Eds.). Mahwah: Lawrence Erlbaum Associates, pp. 125-171, 2005.

[41]. Cooper, J., Blackman, S. and Keller, K., "The Science of Attitudes", New York: Routledge, 2016.

[42]. Olson, M. and Kendrick, R., "Origins of Attitudes", in Attitudes and Attitude Change, Crano, W. and Prislin, R. (Eds.). New York: Psychology Press, pp. 111-130, 2008

[43]. Pathak, A., "Consumer Attitude - A Literature Review", BRDU International Journal of Multidisciplinary Research, 1(8), pp. $30-43,2016$.

[44]. Bravo-Gil, R., Fraj-Andres, E. and Martinez-Salinas, E., "Family as a source of consumer-based brand equity", Journal of Product \& Brand Management, 16(3), pp. 188-199, 2007.

[45]. Durmaz, Y. and Zengin, S., "An Impirical Study on the Effect of Family Factor on Consumer Buying Behaviours", Asian Social Science, 7(10), pp. 53-62, 2011.

[46]. Chikweche, T., Stanton, J. and Fletcher, R., "Family purchase decision making at the bottom of the pyramid", Journal of Consumer Marketing, 29(3), pp. 202-213, 2012.

[47]. Hawkins, D. and Mothersbaugh, D., “Consumer Behavior Building Marketing Strategy”, 11th Ed., New York: McGraw-Hill/Irwin, 2010.

[48]. Solomon, M., "Consumer Behavior. Buying, Having, and Being", 12th Ed., Global Ed., Harlow: Pearson Education, 2018.

[49]. Arsel, Z. and Bean, J., "Taste regimes and market-mediated practice”, Journal of Consumer Research, 39(5), pp. 899-917, 2013.

[50]. Kemper, T., "Elementary Forms of Social Relations: Status, power and reference groups", New York: Routledge, 2017.

[51]. Arnould, E. and Thompson, C., "Consumer culture theory: Twenty years of research", Journal of Consumer Research, 31(4), pp. 868-893, 2005.

[52]. Foxall, G., "Perspectives on Consumer Choice. From Behavior to Action, from Action to Agency", London: Palgrave Macmillan, 2016.

[53]. Lin, J., and Sung, Y., "Nothing can tear us apart: The effect of brand identity fusion in consumer-brand relationships", Psychology \& Marketing, 31, pp. 54-69, 2014.

[54]. Hawkins, M., "The effect of activity identity fusion on negative consumer behavior", Psychology \& Marketing, 36(4), pp. 395-409, 2019.

[55]. Pride, W. and Ferrell, O., "Foundations of Marketing", 8th Ed., Boston: Cengage, 2019. 


\section{International Advanced Research Journal in Science, Engineering and Technology}

Vol. 8, Issue 2, February 2021

\section{DOI: $10.17148 / I A R J S E T .2021 .8222$}

[56]. Edson Escalas, J. and Bettman, J., "Self-Construal, Reference Groups, and Brand Meaning”, Journal of Consumer Research, 32(3), pp. 378-389, 2005

[57]. Peter, P. and Olson, J., "Consumer Behavior \& Marketing Strategy”, 9th Ed., New York: McGraw-Hill/Irwin, 2010.

[58]. Liu, C. and Hogg, M., "The Interplay of The Desired and Undesired Selves in Everyday Consumption”, in The Routledge Companion to Consumer Behavior, Solomon, M. and Lowrey, T. (Eds.). New York: Routledge, 2018.

[59]. Wilson, R. and Gilligan, C., "Strategic Marketing Management: Planning, implementation and control", 3rd Ed., Oxford: Elsevier, 2005.

[60]. Samli, C., "International Consumer Behavior in the 21st Century. Impact on Marketing Strategy Development", New York: Springer, 2013.

[61]. Henry, P. and Caldwell, M., "The Hidden Hand of Social Class", in The Routledge Companion to Consumer Behavior, Solomon, M. and Lowrey, T. (Eds.), pp. 445-458, 2018.

[62]. Moschis, G., "Consumer Behavior over the Life Course. Research Frontiers and New Directions", Cham: Springer, 2019.

[63]. Usunier, J-C. and Lee, J., "Marketing Across Cultures", 4th Ed., Harlow: Pearson Education, 2005.

[64]. De Mooij, M., "Consumer Behavior and Culture: Consequences for Global Marketing and Advertising”, 2nd Ed., Thousand Oaks: Sage, 2011.

[65]. Kacen, J. and Lee, J., “The Influence of Culture on Consumer Impulsive Buying Behavior”, Journal of Consumer Psychology, 12(2), pp. 163$176,2002$.

[66]. Talay, B., Townsend, J. and Yeniyurt, S., "Global Brand Architecture Position and Market-Based Performance: The Moderating Role of Culture", Journal of International Marketing, 23(2), pp. 55-72, 2015.

[67]. Stephens, D., "Essentials of Consumer Behavior", New York: Routledge, 2017.

[68]. Cayla, J., Beers, R. and Arnould, E., "Stories That Deliver Business Insights", MIT Sloan Management Review, 55(2), pp. 55-62, 2014.

[69]. Yaprak, A., Prince, M., "Consumer morality and moral consumption behavior: literature domains, current contributions, and future research questions", Journal of Consumer Marketing, 36(3), pp. 349-355, 2019.

[70]. Shavitt, S., Lee, A. and Torelli, C., "Cross-Cultural Issues in Consumer Behavior”, in Social Psychology of Consumer Behavior, Wänke, M., (Ed.). New York: Taylor \& Francis Group, pp. 227-250, 2009.

[71]. Mason, R. and Wigley, G., "The 'chav' Subculture: Branded Clothing as an Extension of the Self”, Journal of Economics and Behavioral Studies, 5(3), pp. 173-184, 2013.

[72]. Akestam, N., Rosengren, S. and Dahlen, M., "Think about It - Can Portrayals of Homosexuality in Advertising Prime Consumer-perceived Social Connectedness and Empathy?", European Journal of Marketing, 51(1), pp. 82-98, 2017.

[73]. Kahr, A., Nyffenegger, B., Krohmer, H. and Hoyer., W., "When Hostile Consumers Wreak Havoc on Your Brand: The Phenomenon of Consumer Brand Sabotage”, Journal of Marketing, 80(3), pp. 25-41, 2016. 